\title{
Mapeando os Estudos de Novas Mídias no Brasil ${ }^{1}$
}

\section{Paula Guimarães Simões, Vera Regina Veiga França, Ana Karina Oliveira, Laura Antônio Lima, Lucas Afonso Sepulveda, Lívia Barroso, Maria Lúcia Afonso, Suzana Lopes, Maíra Lobato, Paulo Basílio, Clara Bontempo, Samuel Pereira}

As autoras e os autores do texto são membros do Grupo de Pesquisa em Imagem e Sociabilidade da Universidade Federal de Minas Gerais (GRIS/UFMG). Integram o projeto de pesquisa As Novas Teorias da Comunicação: mapeamento de um campo científico, coordenado pelas professoras Vera França (PPGCOM/UFMG) e Paula Simões (PPGCOM/UFMG) e desenvolvido com o apoio da CAPES, do CNPq, da FAPEMIG e da PRPq/UFMG (instituições às quais agradecemos). A pesquisa investiga os alicerces teóricos das áreas temáticas que configuram o Campo da Comunicação no Brasil e já tratou de seis áreas: Comunicação e Política, Estudos de Televisão, Novas Mídias, Estudos de Jornalismo, Epistemologia da Comunicação e Comunicação e Sociabilidade.

E-mail de contato: grisufmg@gmail.com

Submetido em 28 de Janeiro de 2019 Aceito em: 20 de Junho de 2019

\section{RESUMO}

A proposta do artigo é identificar autores/as e teorias utilizadas como referência por pesquisadores/as da área de Novas Mídias no Brasil. 0 corpus selecionado inclui 100 artigos da Compós durante o período de 2006 a 2015. Essa apresentação

\footnotetext{
${ }^{1}$ Este texto apresenta resultados da pesquisa As novas teorias da Comunicação: mapeamento de um campo científico. Para conhecer os resultados de outras áreas mapeadas, cf: França et al, 2016, 2018; Simões et al, 2019. Agradecemos ao CNPq, à CAPES, à FAPEMIG e à PRPq/UFMG o apoio ao desenvolvimento de nossas pesquisas.
}

Dossiê Espaço Urbano e Imaginação Cultural - https://revistaecopos.eco.ufrj.br/

ISSN 2175-8689 - v. 22, n. 3, 2019

DOI: 10.29146/eco-pos.v22i3.23013 
específica faz parte de uma pesquisa mais ampla que almeja apreender as teorias contemporâneas que alicerçam o campo da Comunicação no país. A análise destaca a ênfase das pesquisas na questão da técnica, associada ao poder, buscando compreender o papel das novas tecnologias na configuração da sociedade, da subjetividade dos indivíduos e de seus processos cognitivos.

PALAVRAS-CHAVE: Teorias da Comunicação, Epistemologia da Comunicação, Novas Mídias.

\section{ABSTRACT}

The purpose of the article is to identify authors and theories used as central references by Brazilian researchers in the area of New Media. The empirical corpus includes 100 articles presented at Compós in a period of ten years (2006-2015). The paper is part of a broader research that aims to apprehend the contemporary theories that underpin the field of Communication in the country. The analysis identifies many studies that focus on the question of technique, associated with power relations. These studies often seek to understand the role of new technologies in the configuration of society, individuals' subjectivity and cognitive processes.

KEYWORDS: Theories of Communication, Epistemology of Communication, New Media.

\section{RÉSUMÉ}

Cet article envisage identifier les auteurs et les théories qui sont référencées par les chercheurs/chercheuses dans le domaine des Sciences et Technologies du Numérique au Brésil. Le corpus de cette étude inclut 100 articles présentés dans les Séminaires Nationaux de la Compós pendant la période 2006-2015. Elle fait partie d'un projet de recherche plus étendu à propos des théories contemporaines qui fondent les études de la Communication au pays. Notre analyse met en évidence l'importance accordée par ces études à la question de la technique, tout comme à la question du pouvoir qui lui est associée. Ce qui ressort aussi c'est le rôle des nouvelles technologies dans la configuration de la société, de la subjectivité des individus et du processus cognitifs.

MOTS CLÉS: Théories de la Communication, Epistémologie de la Communication, Sciences et Technologies du Numérique

Dossiê Espaço Urbano e Imaginação Cultural - https://revistaecopos.eco.ufrj.br/

ISSN 2175-8689 - v. 22, n. 3, 2019

DOI: 10.29146/eco-pos.v22i3.23013 


\section{Introdução}

É inegável a presença da Internet em nossas vidas, e inúmeros são os pesquisadores e pesquisadoras que vêm buscando compreender sua inserção na sociedade contemporânea. Estudos vêm sendo realizados sobre o Facebook, o Twitter, o Instagram e o Youtube, por exemplo, buscando compreender o papel dessas plataformas em acontecimentos políticos, em movimentos sociais, na construção da imagem pública de celebridades, entre tantas outras possibilidades de análise. Com o desenvolvimento acelerado de tais dispositivos, nos últimos anos, um certo patrimônio de pesquisas foi se consolidando em torno do tema, trazendo o desafio de se compreender como tais investigações vêm sendo delineadas no campo da Comunicação.

É justamente este o objetivo deste artigo: apreender a configuração dos estudos voltados às Novas Mídias no Brasil, buscando identificar quais são os autores e autoras mais referenciados e quais as principais perspectivas teóricas acionadas na compreensão dos fenômenos que compõem a cibercultura. 0 texto apresenta parte dos resultados de uma pesquisa mais ampla que procura mapear 0 campo da Comunicação no Brasil a partir de suas áreas temáticas (tais como Comunicação e Política e Estudos de Televisão, entre outras). Esse mapeamento vem sendo feito a partir dos textos apresentados no evento anual da Compós (Associação dos Programas de Pós-Graduação em Comunicação) em um período de 10 anos (2006-2015). ${ }^{2}$ No caso da área de Novas Mídias, o corpus de análise é composto por 100 textos coletados no GT Comunicação e Cibercultura nesse período.

Outros esforços já foram realizados na tentativa de mapear essa área temática no Brasil. Em texto de 2006, Denize Corrêa já apontava que, apesar de incipiente, a área apresentava certo nível de organização: 10 programas de pós-

\footnotetext{
2 Todos os textos foram coletados no site da instituição, onde são disponibilizados os anais dos encontros da Compós: http://www.compos.org.br/anais.php.
}

\section{Dossiê Espaço Urbano e Imaginação Cultural - https://revistaecopos.eco.ufrj.br/ \\ ISSN 2175-8689 - v. 22, n. 3, 2019 \\ DOI: 10.29146/eco-pos.v22i3.23013}


graduação em universidades variadas com linhas relacionadas ao tema e 11 grupos de pesquisa cadastrados no CNPq. A pesquisadora também agrupa os interesses da área em cinco clusters temáticos: 1) Cibercidades e Mobilidades; 2) Imaginários da Cibercultura; 3) Imersão e Interfaces; 4) Jornalismo Digital; 5) Web Sociabilidades/Subjetividades.

Em 2013, Martino identifica que, apesar do grande volume de pesquisas explorando as problemáticas da Cibercultura, a discussão sobre os fundamentos epistemológicos das teorias que orientam os estudos dessa área ainda não foi convenientemente desenvolvida. Seu objetivo, no texto, foi apreender articulações e limites entre as Teorias da Comunicação e as Teorias da Cibercultura, sistematizando os principais eixos temáticos explorados no campo da Cibercultura a partir de autores internacionais de referência.

Em trabalho mais recente, Recuero (2015) analisa o mesmo corpus de textos que o presente artigo, ou seja, os 100 trabalhos apresentados no GT de Cibercultura da Compós entre 2006 e 2015. Seu objetivo foi identificar e mensurar a presença de temas e coautorias no grupo, atentando para as possibilidades de colaboração entre os pesquisadores e pesquisadoras dessa área temática. No que tange às temáticas, Recuero identifica dois períodos: uma maior ênfase nas redes sociais, cultura digital e vigilância nos anos 2006-2010; e uma maior diversificação nos anos 2011-2015, quando aparece também a temática da cognição, jogos e a teoria do ator-rede.

0 trabalho aqui apresentado se soma a esses esforços em uma tentativa de mapear esta área temática nomeada de Cibercultura ou Novas Mídias no Campo da Comunicação no Brasil.

\section{Metodologia e Resultados Quantitativos ${ }^{3}$}

\footnotetext{
${ }^{3}$ A metodologia da pesquisa é apresentada de forma mais detalhada em artigos que apresentam os resultados das outras áreas temáticas (cf. Autores/as, 2018, 2019a, 2019b).
}

\section{Dossiê Espaço Urbano e Imaginação Cultural - https://revistaecopos.eco.ufrj.br/ \\ ISSN 2175-8689 - v. 22, n. 3, 2019 \\ DOI: 10.29146/eco-pos.v22i3.23013}


A partir do corpus delineado, apreendemos algumas informações descritivas da área:

- $\quad$ quantidade de pesquisadores/as (autores dos artigos) $=76$

- quantidade de autores referência $=1430-1184$ estrangeiros, 246 brasileiros, (46 são membros do GT)

- proporção estrangeiros/brasileiros $=4,8$

Comparando às outras áreas que já analisamos (Comunicação e Política e Estudos de Televisão), Novas Mídias apresenta um maior número de autores estrangeiros em relação aos brasileiros: enquanto a proporção das outras duas áreas é de 2/1, Novas Mídias conta com quase cinco vezes mais referências estrangeiras do que brasileiras.

0 quadro a seguir apresenta as 10 referências mais citadas durante o período. Apenas 2 brasileiros compõem o ranking: André Lemos (que é membro do GT Comunicação e Cibercultura) e Lúcia Santaella. Os demais pesquisadores todos homens - são estrangeiros, sendo que 5 são franceses.

Nos casos de empate entre as referências, o critério utilizado foi a quantidade de artigos diferentes que citam aquele autor ou autora, dado indicativo de uma maior difusão do pensamento dentro do campo.

Quadro 1. Dez autores/as mais referenciados/as nos trabalhos da Compós área de Novas Mídias (2006-2015)

\begin{tabular}{|c|c|c|c|c|}
\hline No & Nome & $\begin{array}{c}\text { Frequência } \\
\text { das } \\
\text { referências }\end{array}$ & Brasileiro/a & $\begin{array}{c}\text { Instituição dos } \\
\text { autores/as }\end{array}$ \\
\hline $\mathbf{1}$ & FOUCAULT, Michel & 45 & Não & Collège de France \\
\hline $\mathbf{2}$ & LATOUR, Bruno & 40 & Não & $\begin{array}{c}\text { Science Po e Horschule } \\
\text { für Gestaltung }\end{array}$ \\
\hline
\end{tabular}

Dossiê Espaço Urbano e Imaginação Cultural - https://revistaecopos.eco.ufrj.br/

ISSN 2175-8689 - v. 22, n. 3, 2019

DOI: 10.29146/eco-pos.v22i3.23013 


\begin{tabular}{|c|c|c|c|c|}
\hline $\mathbf{3}$ & $\begin{array}{c}\text { BAUDRILLARD, } \\
\text { Jean }\end{array}$ & 30 & Não & $\begin{array}{c}\text { Universidade de } \\
\text { Paris X }\end{array}$ \\
\hline $\mathbf{4}$ & LEMOS, André & 28 & Sim & UFBA \\
\hline $\mathbf{5}$ & DELEUZE, Gilles & 27 & Não & $\begin{array}{c}\text { Universidade de } \\
\text { Vincennes }\end{array}$ \\
\hline $\mathbf{6}$ & SANTAELLA, Lucia & 24 & Sim & PUC-SP \\
\hline $\mathbf{7}$ & CASTELLS, Manuel & 21 & Não & $\begin{array}{c}\text { Universidade do Sul } \\
\text { da Califórnia }\end{array}$ \\
\hline $\mathbf{8}$ & FLUSSER, Vilém & 17 & Não & $\begin{array}{c}\text { Escola Politécnica - } \\
\text { USP }\end{array}$ \\
\hline $\mathbf{9}$ & $\begin{array}{c}\text { VIRILIO, Paul } \\
\text { European Graduate } \\
\text { School }\end{array}$ \\
\hline $\mathbf{1 0}$ & $\begin{array}{c}\text { R HEINGOLD, } \\
\text { Howard }\end{array}$ & 16 & Não & $\begin{array}{c}\text { Universidade da } \\
\text { Califórnia - Berkeley }\end{array}$ \\
\hline
\end{tabular}

Fonte: construção nossa com dados da pesquisa

O quadro 2 apresenta as obras mais citadas durante o período analisado, com a liderança de uma obra de Bruno Latour, grande presença no campo, seguida de uma obra de André Lemos. As frequências consideram as citações da mesma obra em línguas diferentes, que são agrupadas.

Quadro 2. Obras mais citadas pelos trabalhos da Compós na área de Novas Mídias (2006-2015)

\begin{tabular}{|c|c|c|c|}
\hline № & Obra & Autor/a & $\begin{array}{c}\text { Frequência } \\
\text { de citações }\end{array}$ \\
\hline $\mathbf{1}$ & $\begin{array}{c}\text { Reassembling the social }+ \\
\text { Reagregando o Social }\end{array}$ & LATOUR, B. \\
\hline $\mathbf{2}$ & $\begin{array}{c}\text { Cibercultura: tecnologia e } \\
\text { vida social }\end{array}$ & LEMOS, A. & 10 \\
\hline
\end{tabular}

Dossiê Espaço Urbano e Imaginação Cultural - https://revistaecopos.eco.ufrj.br/

ISSN 2175-8689-v. 22, n. 3, 2019

DOI: 10.29146/eco-pos.v22i3.23013 


\begin{tabular}{|c|c|c|c|}
\hline 3 & $\begin{array}{c}\text { Remediation: } \\
\text { understanding new media }\end{array}$ & BOLTER, J.D.; GRUSIN, R. & 10 \\
\hline 4 & $\begin{array}{c}\text { Mille Plateaux + Thousand } \\
\text { Plateaus + Mil Platôs }\end{array}$ & DELEUZE, G.; GUATTARI, F. & 10 \\
\hline 5 & $\begin{array}{l}\text { Culturas e artes do pós- } \\
\text { humano }\end{array}$ & SANTAELLA, L. & 10 \\
\hline 6 & Cultura da convergência & JENKINS, H. & 9 \\
\hline 7 & $\begin{array}{c}\text { A cauda longa }+ \text { The } \\
\text { Long Tail }\end{array}$ & ANDERSON, C. & 9 \\
\hline 8 & $\begin{array}{l}\text { A sociedade em Rede }+ \\
\text { The Rise of Network } \\
\text { Society }\end{array}$ & CASTELLS, M. & 9 \\
\hline 9 & $\begin{array}{c}\text { Smart Mobs + Multitudes } \\
\text { Inteligentes }\end{array}$ & RHEINGOLD, H. & 8 \\
\hline 10 & $\begin{array}{c}\text { Hamlet no Holodeck }+ \\
\text { Hamlet on the Holodeck }\end{array}$ & MURRAY, J.H. & 8 \\
\hline 11 & $\begin{array}{c}\text { The strenght of weak ties + } \\
\text { La fuerza de los vínculos } \\
\text { débiles }\end{array}$ & GRANOVETTER, M. & 8 \\
\hline 12 & $\begin{array}{l}\text { Os meios de comunicação } \\
\text { como extensões do homem } \\
\text { + Understanding Media }\end{array}$ & MCLUHAN, M. & 8 \\
\hline
\end{tabular}

Fonte: construção nossa com dados da pesquisa

A seguir, partimos dos autores e autora do Quadro 1 e observamos dois aspectos: como são citados nos artigos em questão e quais as obras mais referenciadas. A partir de uma leitura dessas obras, identificamos seus conceitoschave e sua importância para área, bem como sua utilização nos artigos. 


\section{Autores/as e Perspectivas Convocadas}

\section{1) Michel Foucault}

Foucault (1926-1984) é referenciado 45 vezes, com 21 obras citadas em 19 textos, de 18 pesquisadores/as ${ }^{4}$. Filósofo e professor do Collège de France, onde permaneceu até sua morte, o autor ocupa o primeiro lugar no ranking de teóricos mais citados neste GT. As obras de destaque são Vigiar e Punir, com 7 menções; História da Sexualidade I: A vontade de saber, com 5; e De outros espaços, com 4. Em seguida, estão as obras A Hermenêutica do Sujeito; A Coragem da Verdade; O Governo de Si e dos Outros; e Segurança, Território, População, todas com 3 menções cada uma.

Em Vigiar e Punir (1975), uma das obras mais influentes do autor, Foucault faz uma análise da questão da vigilância e da punição em várias instituições sociais como prisões, hospitais e escolas. $\mathrm{O}$ autor critica a ideia de que a prisão é uma forma humanista de punição e aponta as regras que fundam o poder de castigar. A partir delas, o criminoso é colocado em oposição ao cidadão normal e é definido como louco, como mau e como anormal.

No livro História da Sexualidade I: A vontade de saber (1976), Foucault aborda a questão da repressão sexual vivida pela sociedade. 0 autor defende a hipótese de que, a partir do século XVIII, surge uma variedade de discursos sobre sexo a partir de instituições como a igreja, a escola, a família e a medicina, que visam ao controle dos indivíduos e da população.

Na obra A Hermenêutica do Sujeito (1981-1982), Foucault analisa as sociedades arcaicas e trata da relação entre filosofia e espiritualidade, fazendo uma análise do princípio "conhece-te a ti mesmo" de Platão. 0 autor analisa a história do cuidado e das técnicas de si, retomando os períodos Socrático-Platônico (séc. IV a.C.); Helenístico-Romano (séc. I-II d.C.) e Ascético-Monástico (séc. III-IV d.C.) para fazer uma história da subjetividade.

\footnotetext{
${ }^{4}$ Entre os/as pesquisadores/as, incluímos autores/as e coautores/as.

Dossiê Espaço Urbano e Imaginação Cultural - https://revistaecopos.eco.ufrj.br/

ISSN 2175-8689 - v. 22, n. 3, 2019

DOI: 10.29146/eco-pos.v22i3.23013
} 
Em De outros espaços (1967), o autor parte da tese de que o século XX é o século do espaço, ressaltando a importância da história do espaço para a sociedade ocidental. Ele faz uma distinção entre espaço de localização (medieval), de extensão (evidenciado por Galileu) e de alocação (contemporâneo). Em relação ao espaço de alocação, Foucault aponta dois grandes tipos: utopias e heterotopias.

A obra A Coragem da Verdade (1984) foi o último curso ministrado por Foucault no Collège de France, em 1984, pouco tempo antes de morrer. Nela, o tema da morte é muito presente. 0 autor busca questionar os modos de constituição ética dos sujeitos por meio da coragem de dizer-a-verdade (parresía). Foucault demonstra que a constituição de modos de ser (ethos) exige uma relação afetiva do indivíduo consigo mesmo e com o outro.

Em O Governo de Si e dos Outros (1983), o autor propõe a indissociabilidade entre ética e política. A partir da questão "Qual governo de si deve ser o fundamento e o limite ao governo dos outros?", ele aponta que o cuidado de si não pode ser compreendido sem o cuidado dos outros e problematiza o status de sua própria fala.

Segurança, Território, População (1977-1978) desenvolve a genealogia de uma forma de saber político centrado nos mecanismos que possibilitam a regulação da população. Ele trata de uma nova proposição sobre a análise dos mecanismos de poder: o biopoder. Nesta obra, Foucault aborda o papel da polícia como garantidora da ordem interna e técnica de controle populacional e trabalha o conceito de biopolítica.

É interessante observar que o autor mais citado no campo de estudo das Novas Mídias não trata de mídia e nem, a rigor, da Comunicação - mas das relações de poder e da constituição do sujeito (o sujeito submetido às instituições, o governo e o cuidado de si).

\title{
2) Bruno Latour
}

Latour (1947 - ) é o segundo autor mais citado, com um total de 40 referências, em 20 artigos diferentes. Professor do Institut d'Etudes Politiques de

\author{
Dossiê Espaço Urbano e Imaginação Cultural - https://revistaecopos.eco.ufrj.br/ \\ ISSN 2175-8689 - v. 22, n. 3, 2019 \\ DOI: 10.29146/eco-pos.v22i3.23013
}


Paris, o autor teve 18 obras citadas por 15 pesquisadores/as. Sua obra Reagregando o social é a mais citada da área, aparecendo 12 vezes. A segunda, com 5 citações, é o capítulo "Where are the missing masses? The sociology of a few mundane artifacts", seguida de On Technical Mediation. Philosophy, Sociology, Genealogy, com 4 citações, e Jamais fomos modernos, com 3 citações.

Reagregando o social: uma introdução à teoria ator-rede (2005) apresenta conceitos que o autor já vinha desenvolvendo sobre a teoria social e o conceito de sociedade. Através do que ele chama sociologia de associações, o autor recupera os sentidos da palavra "social", apontando as falhas em seu uso e a maneira como devemos pensá-la. A teoria ator-rede ficou popularmente conhecida por atribuir agência a objetos inanimados, mas não se resume a isso. 0 que Latour desenvolve nessa obra é um projeto que dê conta do fim da modernidade e se "engaje em cosmopolíticas", saia do conforto de uma sociologia da ciência ocidentalizada e imagine novas configurações de mundo.

"Where are the missing masses? The sociology of a few mundane artifacts" (1992) é um capítulo em que o autor discute como artefatos criados por seres humanos conseguem restringir e modelar as ações destes, além de conseguirem substituí-las em determinadas circunstâncias. São as implicações das tecnologias na maneira como enxergamos e vivemos no mundo que interessam ao pesquisador; como elas afetam nosso cotidiano e transformam nossa sobrevivência mediando as relações humanas, sempre tendo em vista as tensões políticas que permeiam as sociedades.

On Technical Mediation. Philosophy, Sociology, Genealogy (1994) é composto por três "lectures" em que se propõe a superação do paradigma dualista que separa humanos de não-humanos. 0 antropólogo desenvolve um caminho explicativo da evolução da civilização, mostrando como a mediação técnica é fonte da força moral e política das sociedades atuais.

Jamais fomos modernos (1991) é um ensaio sobre o conceito de modernidade, em que o autor questiona a divisão vigente entre a sociedade

\section{Dossiê Espaço Urbano e Imaginação Cultural - https://revistaecopos.eco.ufrj.br/ \\ ISSN 2175-8689 - v. 22, n. 3, 2019 \\ DOI: 10.29146/eco-pos.v22i3.23013}


ocidental moderna e "os outros" não modernos. Para isso, sua proposta é retomar uma das questões primordiais da antropologia - a separação entre natureza e cultura -, assim como abandonar a modernidade, tentando articular os conceitos de hibridismo, crítica, redes, tradução e simetria.

Latour, sem dúvida, é um autor que traz a questão da técnica e da tecnologia para o centro de sua reflexão, enfatizando a agência dos atores não-humanos e buscando compreender a inserção das tecnologias em nosso cotidiano. Por este caminho, Latour procura apresentar uma nova leitura do contemporâneo.

\section{3) Jean Baudrillard}

Baudrillard (1929-2007) vem em seguida, com 10 obras citadas 30 vezes em 11 artigos, por 8 pesquisadores/as. Sociólogo e filósofo pós-modernista, suas obras mais citadas foram os livros Simulacros e simulação, com 7 citações; As estratégias fatais e A transparência do mal, com 4 cada.

Em Simulacros e simulação (1981), Baudrillard desenvolve o conceito de simulacro como uma resultante da repetição incessante de um significante sem qualquer relação com a realidade, produzindo o que ele chama de hiper-real. Baudrillard é bastante pessimista quanto ao contexto contemporâneo, especialmente em relação aos meios de comunicação de massa, que seriam os principais responsáveis pela propagação e produção dos simulacros. Através de sua dinâmica massiva de repetição, os meios construiriam representações, tomadas por nós como a própria realidade.

Em As estratégias fatais (1983), Baudrillard dá continuidade à noção de hiper-real a partir das banalidades da vida moderna, identificando nelas características tipicamente pós-modernas que irão compor o que ele denomina cultura do simulacro. São elas: a proximidade absoluta e instantânea das coisas, o fim da intimidade do sujeito, a superexposição e transparência do mundo, o fim da cena e a assunção do obsceno. Os meios de comunicação desempenham mais uma vez um papel central, pois são eles quem reproduzem e repetem continuamente

Dossiê Espaço Urbano e Imaginação Cultural - https://revistaecopos.eco.ufrj.br/

ISSN 2175-8689 - v. 22, n. 3, 2019

DOI: 10.29146/eco-pos.v22i3.23013 
imagens do real que não teriam qualquer ligação verdadeira com ele, produzindo simulacros.

No livro ensaístico A transparência do mal (1990), o autor destaca os efeitos do capitalismo contemporâneo nas estruturas mentais do sujeito moderno, utilizando-se novamente da noção de simulacro. Através da repetição, construímos cenas já vividas, em busca de utopias que já teriam sido superadas, mas somos incapazes de percebê-las como tal.

Baudrillard apresenta uma visão bastante pessimista da sociedade atual - a pós-modernidade - , na qual os meios têm um papel preponderante de simulação e obscurecimento do real. A referência ao autor no contexto dos textos sobre Novas Mídias significa, assim, estender à atuação das redes sociais o mesmo contexto de superexposição do sujeito e criação de simulacros.

\section{4) André Lemos}

André Lemos aparece com 28 citações em 20 artigos, por 19 pesquisadores/as. Professor da UFBA e fundador da Associação Brasileira de Pesquisadores em Cibercultura (ABCIBER), teve 17 diferentes obras citadas. Dentre elas, 2 livros se destacam: Cibercultura: tecnologia e vida social na cultura contemporânea, com 8 citações; e A comunicação das coisas: teoria ator-rede e cibercultura, com 3.

Cibercultura: tecnologia e vida social na cultura contemporânea (2002) discute a relação global e histórica entre técnica e sociedade, para situar a cibercultura no contexto contemporâneo. Lemos enfatiza o caráter social da cibercultura, entendida como "uma sinergia entre a vida social e os dispositivos eletrônicos e suas redes telemáticas" (Lemos, 2002, p.10), que se encontra intrinsecamente associada às redefinições de espaço e tempo, sujeito e objeto, comunidade e indivíduo, natureza e artifício, real e virtual que caracterizam a sociedade contemporânea (Lemos, 2002, p.268).

\section{Dossiê Espaç̧o Urbano e Imaginação Cultural - https://revistaecopos.eco.ufrj.br/ \\ ISSN 2175-8689 - v. 22, n. 3, 2019 \\ DOI: 10.29146/eco-pos.v22i3.23013}


Em A comunicação das coisas: teoria ator-rede e cibercultura (2013), Lemos parte da obra de Latour (apresentado anteriormente), enfatizando que sujeitos e objetos são híbridos. Distanciando-se da ideia de que objetos não-humanos são completamente passivos e dominados por humanos, defende que coisas (objetos inteligentes como computadores, servidores, redes, sensores e smartphones) também comunicam - entre si e com humanos.

Lemos tem um papel importante no cenário do estudo das mídias digitais no país, pois oferece um foco exclusivo nas novas tecnologias e sua relação com a vida social.

\section{5) Gilles Deleuze}

Deleuze (1925-1995) apresenta 27 ocorrências, em 13 textos por 12 pesquisadores/as. O filósofo, que foi professor das universidades de Vincennes, Lyon e Sorbonne, teve 9 de suas obras referenciadas, sendo os livros mais citados Mil Platôs: Capitalismo e Esquizofrenia ${ }^{5}$ (escrito em parceria com Félix Guattari, 10 ocorrências); Foucault (6)6; e Conversações (5).

Mil Platôs: Capitalismo e Esquizofrenia (1995) apresenta o conceito de rizoma, que "não começa nem conclui, ele se encontra sempre no meio, entre as coisas, inter-ser, intermezzo" (Deleuze; Guattari, 1995a, capa do livro). A obra é organizada em "platôs", que seriam mapas ou diagramas nos quais os conceitos são construídos. Cada platô pode ser lido de modo independente, mas todos são profundamente articulados uns aos outros, tal como os conceitos neles desenvolvidos - rizomáticos. Ao todo, são quinze platôs que discutem alguns dos conceitos e termos que se tornaram centrais ao pensamento e ao vocabulário deleuzianos, como agenciamento, devir, rizoma, máquinas de guerra, linhas de fuga, molar e molecular, entre outros.

\footnotetext{
${ }^{5}$ A obra Mil Platôs: Capitalismo e Esquizofrenia foi publicada no Brasil em cinco volumes, e apenas dois entre os dez autores que citam a obra referenciam o volume utilizado (em ambos os casos, o primeiro volume). Dessa forma, a obra será aqui abordada em sua totalidade.

${ }^{6} \mathrm{Em}$ um dos seis casos, é referenciado apenas o capítulo "As estratégias ou o não-estratificado: o pensamento do lado de fora (poder)".
}

Dossiê Espaço Urbano e Imaginação Cultural - https://revistaecopos.eco.ufrj.br/

ISSN 2175-8689 - v. 22, n. 3, 2019

DOI: 10.29146/eco-pos.v22i3.23013 
Em Foucault (2005), Deleuze percorre a filosofia de Michel Foucault a partir de suas principais obras, identificando as origens de alguns conceitos, como fora, dobra, subjetivação, vontade de verdade, poder, saber, homem infame, entre outros. As aproximações e divergências de Foucault com outros autores também são analisadas, principalmente em relação a Blanchot e Nietzsche.

Conversações (2013) traz uma série de entrevistas, textos e ensaios publicados entre 1972 e 1990, em que ele fala sobre cinema, Foucault e sobre suas obras anteriores. A propósito de $O$ Anti-Édipo e Mil Platôs, o autor defende a abertura para uma livre circulação do pensamento entre filosofia, arte, ciência, literatura, psicanálise, linguística. Deleuze argumenta que a Filosofia é criadora e não reflexiva, e que deve manter uma relação com a não-filosofia. Destaca também a questão da imanência e o interesse em experimentações, multiplicidades e singularidades ao invés da unidade, reflexão e interpretação transcendentes, que buscam universalidades. Ao final, Deleuze fala sobre a importância do político em sua vida e em sua obra e remete, novamente, à obra de Foucault, dando continuidade ao seu pensamento sobre o poder, ao falar sobre sociedades de controle.

Assim como Foucault (a quem ele cita e com quem guarda grande afinidade), Deleuze não trata das tecnologias e da mídia, mas oferece uma visada filosófica centrada na questão do sujeito, da subjetivação, do poder. 0 leque de conceitos criados pelo filósofo enfatiza o tratamento das articulações e das singularidades.

\section{6) Lucia Santaella}

Santaella (1944 - ) é referenciada 25 vezes, com 12 obras citadas em 17 textos publicados por 18 autores/as. Professora da PUC-SP e fundadora do Grupo de Pesquisa em Computação, Semiótica e Games, ocupa o sexto lugar no ranking. A obra mais citada da autora é Cultura e artes do pós-humano: da cultura das mídias à cibercultura, com dez menções. As demais obras aparecem com apenas uma ou duas citações.

\section{Dossiê Espaço Urbano e Imaginação Cultural - https://revistaecopos.eco.ufrj.br/ \\ ISSN 2175-8689 - v. 22, n. 3, 2019 \\ DOI: 10.29146/eco-pos.v22i3.23013}


Em Cultura e artes do pós-humano: da cultura das mídias à cibercultura (2010), a autora apresenta uma reflexão sobre a passagem da cultura de massa (técnicas de reprodução de massa) para cultura das mídias (eletrônicas), e desta para a era digital. As diferentes mídias, através do tipo de comunicação que possibilitam e dos signos que fazem circular, afetam os seres humanos e criam novos ambientes socioculturais. As complexidades semióticas trazidas pelas mídias digitais alteram os ambientes comunicacionais, formam novas linguagens e afetam as formações psicossociais, bem como a constituição do sujeito cultural.

Nesta perspectiva, Santaella enfatiza particularmente as relações entre a máquina e o corpo humano, a cibernética de segunda ordem e o bioconstrutivismo, falando do advento do pós-humano, com as múltiplas realidades do corpo - corpo simulado, corpo digitalizado, corpo biocibernético. A autora também desenvolve um olhar específico sobre o campo das artes, da arte tecnológica e do hibridismo das artes. Sua reflexão é fundada no terreno da filosofia, semiótica, psicanálise, história da arte e das tecnologias.

Santaella atenta para a criação de novos ambientes socioculturais proporcionados pelo surgimento de diferentes mídias e linguagens. A autora também enfatiza a relação entre a máquina e o corpo, falando do advento do póshumano.

\section{7) Manuel Castells}

Castells (1942 - ) teve 21 citações em 16 artigos de 19 pesquisadores/as. Professor das Universidades da Califórnia e do Sul da Califórnia e membro de academias de ciência na América e Europa, teve 8 obras referenciadas, sendo a mais citada $A$ sociedade em rede, com 9 aparições. A segunda obra mais citada é Comunicação e Poder, com 5 referências

A sociedade em rede (2009) é um dos livros que compõem a trilogia $A$ era da informação: economia, sociedade e cultura, obra de fôlego e marco de sua carreira. Nesse volume, o autor busca esclarecer a dinâmica econômica e social da nova era

Dossiê Espaço Urbano e Imaginação Cultural - https://revistaecopos.eco.ufrj.br/

ISSN 2175-8689 - v. 22, n. 3, 2019

DOI: 10.29146/eco-pos.v22i3.23013 
da informação, apresentando uma teoria que busca dar conta dos efeitos fundamentais da tecnologia da informação nas dinâmicas que atravessam o mundo contemporâneo. 0 autor conceitua a economia global como fluxo - ou troca instantânea de informação, capital e comunicação - que regula o consumo e a produção.

Em Comunicação e Poder (2015), seu objetivo é compreender como as mediações da comunicação fazem parte e estão relacionadas às relações de poder, através de vários estudos de caso.

Este também é um autor que lida com a sociedade da informação, porém sua ênfase se dirige à dinâmica sociocultural e relações de poder.

\section{8) Vilém Flusser}

Vilém Flusser (1920-1991) foi citado 17 vezes por 8 pesquisadores/as em 8 textos. Filósofo tcheco-brasileiro, teve 11 obras referenciadas. Filosofia da Caixa Preta: ensaios para uma futura filosofia da fotografia se destaca, tendo sido citada 5 vezes nesse período.

Filosofia da Caixa Preta (2011) apresenta a invenção das imagens técnicas como uma das revoluções fundamentais na estrutura cultural, inaugurando a PósHistória; a outra revolução, para o autor, foi a invenção da escrita linear, que instaurou a História. Para Flusser, as imagens técnicas são imagens produzidas por aparelhos que fazem mediações entre os sujeitos e o mundo; são máquinas complexas cuja função é a produção de significados por meio de uma programação. É neste sentido que o conceito de caixa preta diz respeito a um sistema complexo que, para além de funcionalidades técnicas, traz modelos epistemológicos, políticos e econômicos: o operador desse sistema brinca com ele, mas este lhe é obscuro e indomável.

No cerne da questão está a problematização da determinação e da liberdade, que, para o autor, é do que trata, em última análise, toda e qualquer filosofia. Sua

\section{Dossiê Espaç̧o Urbano e Imaginação Cultural - https://revistaecopos.eco.ufrj.br/ \\ ISSN 2175-8689 - v. 22, n. 3, 2019 \\ DOI: 10.29146/eco-pos.v22i3.23013}


preocupação é com a possibilidade de a programação tolher a liberdade do ser humano de significar e de ler o mundo.

Desta maneira, Flusser estabelece uma relação entre as invenções tecnológicas e as etapas da cultura humana, problematizando, nesse contexto, o lugar do sujeito.

\section{9) Paul Virilio}

Com 16 citações em 8 artigos por 7 pesquisadores/as, Virilio (1932-2018) é o nono autor no ranking. Professor e diretor de estudos da Escola Especial de Arquitetura (Paris) e da Faculdade Internacional de Filosofia de Paris, teve 9 obras citadas. Dentre elas, 3 se destacam, cada uma com 3 citações: La vitesse de libération, A Inércia Polar e O Espaço Crítico.

Em La vitesse de libération (1995), Paul Virilio discute as noções de tempo e de espaço em função do acelerado desenvolvimento tecnológico, sobretudo no pósguerra. Para o autor, a ideia de um tempo cronológico e imutável, assim como de espaço, passa a ser mundializada. Essas dimensões não são mais pautadas exclusivamente por variáveis físicas, mas sobretudo a partir da velocidade e da lógica da informação. 0 autor critica a (falsa) impressão de que o progresso tecnológico promove uma horizontalização dos fluxos, principalmente nos meios digitais. A louvação da tecnologia obscurece uma hierarquia cada vez maior de informações, concentradas e administradas por poucos e poderosos grupos, com capacidade de fortes intervenções no cotidiano. Nesse sentido, para o autor, é de fundamental importância levar em consideração a matriz política de toda tecnologia.

Em A Inércia Polar (1993), o autor relaciona a noção de inércia com estados de movimento que as tecnologias proporcionam ou exigem dos seres humanos. Se, por um lado, a velocidade e a instantaneidade das novas tecnologias de transporte e comunicação reduzem distâncias e ampliam o espaço em que vivemos, por outro

\section{Dossiê Espaç̧o Urbano e Imaginação Cultural - https://revistaecopos.eco.ufrj.br/ \\ ISSN 2175-8689 - v. 22, n. 3, 2019 \\ DOI: 10.29146/eco-pos.v22i3.23013}


elas reduzem também a interação e o movimento humanos em relação mais direta com o espaço.

O Espaço Crítico (1997) dá a ver um autor tão filósofo quanto arquiteto. Virilio analisa o ambiente técnico e a "natureza" tecnologizada do ser humano a partir da arquitetura e das políticas urbanas contemporâneas a fim de investigar a consciência ética de um mundo cada vez mais dependente da produção e difusão de imagens e informações. Para Virilio, a tecnologização de uma sociedade está diretamente atrelada à sua militarização; é nesse contexto que o autor lança seu conceito de guerra pura, propondo um armamento crítico para que possamos lutar consciente e eticamente essa guerra da tecnologia na qual estamos involuntariamente engajados.

Virilio é mais um autor que dirige um olhar problematizador para os efeitos das tecnologias e sua relação com o poder.

\section{9) Howard Rheingold}

Howard Rheingold (1947 - ) é um escritor e acadêmico norte-americano, e partilha o nono lugar no ranking, ao lado de Paul Virilio. Ele é referenciado 16 vezes, com 6 obras citadas em 12 artigos, por 13 pesquisadores/as. De suas obras, duas concentram o maior número de citações: Smart Mobs: the next social revolution (Multitudes Inteligentes) (8); e The Virtual Community: homesteading on the eletronic frontier (A comunidade virtual) (5).

The Virtual Commmunity (1994) se debruça sobre as primeiras comunidades virtuais formadas no mundo, seus aspectos e formas de organização e construção, e seus benefícios para os sujeitos participantes. Rheingold procura demonstrar a potencialidade das comunidades virtuais não só para grupos já existentes no mundo real, mas para novas formas de conexão e troca dos cidadãos a um custo relativamente baixo. Ao mesmo tempo, o autor aponta para possibilidades danosas de comercialização desse espaço ocupado pelas comunidades virtuais.

\section{Dossiê Espaç̧o Urbano e Imaginação Cultural - https://revistaecopos.eco.ufrj.br/ \\ ISSN 2175-8689 - v. 22, n. 3, 2019 \\ DOI: 10.29146/eco-pos.v22i3.23013}


Em Smart Mobs (2003), o autor trata do advento das tecnologias móveis em diferentes lugares do mundo para a construção das smart mobs, que estão relacionadas à "nova forma social que se tornou possível através da combinação de computação, comunicação, reputação e noção de localização" (Rheingold, 2003, p.198, tradução nossa). Isto é, seu interesse são as mobilizações sociais ao redor do mundo que utilizam meios digitais e dispositivos eletrônicos móveis para sua própria realização.

Rheingold, portanto, é essencialmente um pensador das novas mídias e das tecnologias digitais, às quais atribui potencialidades de construção de laços e de mobilização.

\section{Leitura dos Autores pelos textos do GT}

\section{1) Michel Foucault}

Dentre os 19 textos que citam as obras de Foucault, encontramos 18 pesquisadores e pesquisadoras, de 13 instituições, sendo elas: UFRJ (5); UNISINOS (3); PUC-MG (2); PUC-SP (2); UNINOVE (2); UFBA (1); UFC (1); UFES (1); UFPE (1); UFRGS (1); PUC-RS (1); PUC-SP (1); CÁSPER LÍBERO (1)7 , numa influência bastante horizontalizada.

Em 13 textos, o autor é convocado como referência central para a discussão dos pesquisadores/as, que fazem, no mínimo, duas menções às obras de Foucault. Dentre as questões e conceitos foucaultianos acionados, destacamos os dispositivos de vigilância, a visibilidade, as relações de poder, o espaço-tempo e a territorialidade, o controle social, a heterotopia, a biopolítica e o biopoder, o dispositivo, a autoria, a sociedade de controle, a morte no imaginário social, a discursividade, o panóptico e o poder disciplinador do olhar, as práticas de registros de si e processos de subjetivação, além da noção de verdade. Em 12 textos, o

\footnotetext{
${ }^{7}$ A soma do número de autores por instituição não é igual ao total de pesquisadores porque BELLO, C. D. e ROCHA, D. C. transitam entre PUC-SP e UNINOVE e FRAGOSO, S. transita entre UFRGS e UNISINOS.
}

Dossiê Espaço Urbano e Imaginação Cultural - https://revistaecopos.eco.ufrj.br/

ISSN 2175-8689 - v. 22, n. 3, 2019

DOI: 10.29146/eco-pos.v22i3.23013 
pensamento de Foucault é reiterado pelos pesquisadores/as. Apenas um dos textos discorda do pensamento do autor e realiza uma crítica à noção de visibilidade, considerada limitada e ultrapassada para refletir sobre a contemporaneidade.

Nos outros 6 textos, Foucault é acionado como uma referência mais pontual, mas não como o conceito central para o artigo. Observamos, assim, que o autor se configura como um importante referencial teórico para o GT.

\section{2) Bruno Latour}

No recorte analisado, Latour é citado por 15 pesquisadores e pesquisadoras, vinculados às seguintes instituições: UFRJ (5); UFBA (4); UERJ (2); UFF (2); UFMG (2); ESPM (1); UFSC (1); UFPB (1) ${ }^{8}$. Percebemos uma adesão mais expressiva ao pensamento do autor no Rio de Janeiro e na Bahia.

Dos 20 artigos, 15 utilizam os conceitos de Latour de maneira bastante evidente, aplicando sua teoria e discutindo seus conceitos à luz de objetos da área, como os games. É interessante notar o crescimento das citações ao longo dos anos, sendo 2014 o ano em que o pesquisador foi mais citado, com 6 artigos mencionando suas obras. Destacamos que Latour é referenciado nos artigos que discutem principalmente a teoria ator-rede e conceitos como simetria, mediadores/tradutores, agência, rede e sociologia da técnica.

Nos demais textos, o autor aparece como referência de fundo, para validar suas discussões.

\section{3) Jean Baudrillard}

O grupo de pesquisadores e pesquisadoras brasileiros que lançam mão de suas contribuições teóricas se encontra mais localizado no Rio Grande do Sul, em São Paulo e no Rio de Janeiro, nas seguintes instituições: PUC-RS (3); PUC-SP (3);

\footnotetext{
8 A soma do número de autores por instituição não é igual ao total de pesquisadores porque POLIANOV, B. B. transita entre ESPM e UFF; e FALCI, C. H. R., entre UFMG e UFSC.
}

\section{Dossiê Espaço Urbano e Imaginação Cultural - https://revistaecopos.eco.ufrj.br/ \\ ISSN 2175-8689 - v. 22, n. 3, 2019 \\ DOI: 10.29146/eco-pos.v22i3.23013}


UNINOVE (2); UERJ (1); UNISINOS (1). ${ }^{9}$ Ele teve 10 obras citadas, 30 vezes, em 11 artigos e por 8 pesquisadores/as.

O aporte teórico mais expressivo do autor é o conceito de simulacro. De um modo geral, os pesquisadores/as brasileiros/as trazem à tona as contribuições de Baudrillard como um ponto de partida para a discussão dos meios de comunicação digital, reafirmando a ideia da centralidade da mídia nas relações de sociabilidade contemporâneas. Outros conceitos acionados são o de transpolítica, hiperreal/hiper-espetacular e imaginário do ciberespaço. Vale destacar que dois pesquisadores despontam como os que mais utilizam a obra do autor no GT: Eugênio Trivinho (PUC-SP), apresentando 11 citações em 4 artigos; e Juremir Machado Silva (PUC-RS), com 10 citações em 2 artigos. Este último pode ser visto como o grande difusor das ideias de Baudrillard, e o responsável pelo grande número de obras de Baudrillard citadas no GT, trazendo 8 das 10 obras levantadas.

\section{4) André Lemos}

André Lemos foi citado em 20 artigos, por 1910 pesquisadores e pesquisadoras de 12 instituições: UFRGS (4); UERJ (3); UNISINOS (3); UFBA (2); UFF (2); UFRJ (2); UTP (1); UCS (1); PUC-MG (1); UFMG (1); UFPB (1); UCPel (1).

O autor é convocado sobretudo para falar sobre a Teoria Ator-Rede e os conceitos de cibercultura e mídia locativa. A partir do conceito de mídia locativa, os pesquisadores/as falam sobre o que tem sido chamado de virada espacial, que caracteriza as novas relações entre o mundo virtual e o mundo real a partir da mobilidade dos dispositivos tecnológicos. Outras questões associadas ao autor são: participação, engajamento e ativismo em redes digitais; blogs pessoais e representação de si; o conceito de apropriação a partir da perspectiva de ciber-

\footnotetext{
9 A soma do número de autores por instituição não é igual ao total de pesquisadores porque BELLO, C. D. e ROCHA, D. C. transitam entre PUC-SP e UNINOVE.

${ }^{10}$ A soma do número de autores por instituição não é igual ao total de pesquisadores porque os pesquisadores RECUERO, R. C. e DOMINGUES, D. transitam, respectivamente, entre UFRGS e UCPel; e UTP e UCS.
}

Dossiê Espaço Urbano e Imaginação Cultural - https://revistaecopos.eco.ufrj.br/

ISSN 2175-8689 - v. 22, n. 3, 2019

DOI: 10.29146/eco-pos.v22i3.23013 
cultura-remix desenvolvida por Lemos; os processos cognitivos na cibercultura; e o imaginário tecnológico despertado pelo tema do pós-humano.

Por fim, é importante registrar que em todos os artigos em que é citado, Lemos aparece - ao lado de outros autores e autoras - como referência importante na área de novas mídias.

\section{5) Gilles Deleuze}

Deleuze é citado por 12 pesquisadores e pesquisadoras, distribuídos entre $8^{11}$ instituições: UFRJ (4); UNISINOS (3); Cásper Líbero (1); UFBA (1); UFC (1); UFES (1); UFRGS (1); USP (1). A UFRJ pode ser destacada por ter sido representada por 4 pesquisadores/as, que somam 6 trabalhos apresentados ${ }^{12}$. É importante registrar que Henrique Antoun, da UFRJ, soma 14 das 27 menções ao autor (8 delas em seus 2 trabalhos apresentados com a coautoria de Fábio Malini, da UFES).

A referência a Deleuze é utilizada com frequência a partir da aproximação do autor ao pensamento de Foucault e da leitura que faz de seus conceitos: destacamse o poder e suas novas formas de operação na contemporaneidade; a subjetivação e os modos de produção de subjetividade; as normas do discurso, que, ao mesmo tempo que o tornam possível, constrangem a produção de enunciados em um contexto.

A noção de sociedade do controle é muito presente nos trabalhos da área, sobretudo no que diz respeito a uma tensão provocada por certa indistinção entre liberdade e controle nas trocas de informação e conteúdo em ambientes virtuais. As ideias de trabalho imaterial e da indistinção entre vida e trabalho também aparecem aí relacionadas. Outro ponto a ser destacado são os conceitos de territorialização e desterritorialização, com atenção à estreita articulação entre esses movimentos e os agenciamentos e linhas de fuga tornados possíveis por eles, além das relações de desejo que os perpassam.

\footnotetext{
11 A pesquisadora Suley Fragoso é identificada, em seu artigo, como vinculada à UFRGS e à Unisinos.

12 A Unisinos possui 3 representantes, mas reunidas em um único texto.
}

Dossiê Espaço Urbano e Imaginação Cultural - https://revistaecopos.eco.ufrj.br/

ISSN 2175-8689-v. 22, n. 3, 2019

DOI: 10.29146/eco-pos.v22i3.23013 
Também pode ser apontado o uso mais pontual de termos frequentes no vocabulário deleuziano, como agenciamento, rizoma, ritornelo, linhas de fuga, dobra, entre outros, que aparecem nos textos - referenciados ou não - , mas que não compõem efetivamente o argumento ou o método dos pesquisadores.

\section{6) Lucia Santaella}

Dentre os textos que citam as 12 obras da autora (uma delas conta com a coautoria de NÖTH, W., e outra de LEMOS, R.), encontramos 18 pesquisadores e pesquisadoras, de 12 instituições: UERJ (4); UNISINOS (3); UFBA (2); PUC-SP (2); UNINOVE (2); UFRGS (2); IFB (1); PUC-MG (1); UFMG (1); UFPB (1); UFF (1); UFRJ $(1)^{13}$.

Santaella é acionada nos artigos a partir de conceitos como pós-humano, cultura das mídias, pós-digital, mídia locativa, teoria ecológica da percepção, nãolugar e hibridação entre modelo panóptico e escópico. Ela é uma referência para abordar assuntos como inteligência artificial, capacidade de reinvenção das mídias (televisão e o rádio) e processos cognitivos estimulados pelas mídias digitais.

Além disso, suas metodologias também são utilizadas nos artigos, de modo que a autora é vista como uma referência importante para as pesquisas em Comunicação e Cibercultura.

\section{7) Manuel Castells}

Castells é citado em 16 artigos diferentes, por 19 pesquisadores e pesquisadoras, oriundos das seguintes instituições: UNISINOS (4); UFRGS (3); UCPel (2); UERJ (2); UFBA (2); UFRJ (2); PUC-MG (1); UFES (1); UFF (1); UFMG (1); UFPE (1); Universidade Duke (1) ${ }^{14}$.

${ }^{13}$ A soma do número de autores por instituição não é igual ao total de pesquisadores porque BELLO, C. D. e ROCHA, D. C. transitam entre PUC-SP e UNINOVE, e REBS, R. R. transitou entre UFRGS e UNISINOS.

14 A soma do número de autores por instituição não é igual ao total de pesquisadores porque os pesquisadores Fragoso, S. e Zago, G. transitam respectivamente entre UFRGS e UNISINOS e UFRGS e UCPel.

\section{Dossiê Espaço Urbano e Imaginação Cultural - https://revistaecopos.eco.ufrj.br/ \\ ISSN 2175-8689 - v. 22, n. 3, 2019 \\ DOI: 10.29146/eco-pos.v22i3.23013}


Os conceitos do autor mais utilizados são: fluxo, mass-self communication, redes, violência, movimentos sociais e redes sociais digitais, convergência, propriedade intelectual e conhecimento, informação, relação entre dispositivos e mercado/economia/negócios, mapeamento de fluxos informacionais, espaço de fluxos. $\mathrm{O}$ autor emerge como um nome consolidado no campo para refletir sobre a relação entre internet e sociedade, a partir de uma perspectiva que enfatiza a dimensão social da técnica.

\section{8) Vilém Flusser}

Vilém Flusser foi citado em 8 artigos por 8 pesquisadores e pesquisadoras, de 8 instituições: UFBA (2); UFC (1); UFPB (1); USP (1); UERJ (1); PUC-MG (1); UFF (1); UFSC (1) 15 .

Flusser é acionado para refletir sobre a importância da história nas teorias da mídia, em oposição à ideia de progresso linear presente em narrativas que tratam as novas tecnologias como uma ruptura radical com o passado. Seu modelo de decomposição da comunicação é resgatado para pensar sobre o surgimento de uma nova forma cultural devido à reorganização da comunicação pelos computadores. A discussão do autor sobre a lógica de programação de aparelhos também é retomada para refletir sobre mudanças na própria cognição de quem os opera. 0 conceito de aparelho é acionado para pensar sobre a postura ética do artista em relação à tecnologia e como as tecnologias de mediação materializam modelos epistemológicos, sociais e cognitivos, os quais são recombinados pela arte feita pelos aparelhos. Aqui, Flusser é posicionado junto a Walter Benjamin e Marshall McLuhan, apontados como os teóricos da mídia responsáveis por tal discussão.

A Filosofia da Caixa Preta é usada como inspiração para pensar a questão da imagem na pós-história, exemplificada na prática costumeira de registro

\footnotetext{
15 A soma do número de autores por instituição não é igual ao total de pesquisadores porque o pesquisador CASTANHEIRA, J. C. S. transita entre as instituições UFSC e UFF.
}

\section{Dossiê Espaç̧o Urbano e Imaginação Cultural - https://revistaecopos.eco.ufrj.br/ \\ ISSN 2175-8689 - v. 22, n. 3, 2019 \\ DOI: 10.29146/eco-pos.v22i3.23013}


audiovisual de si na contemporaneidade (as selfies), ou para pesquisar o Twitter a partir de uma perspectiva filosófica.

\section{9) Paul Virilio}

Virilio é citado em 8 artigos, por 7 pesquisadores e pesquisadoras de 6 instituições: UNISINOS (3); UFBA (1); UFRGS (1); PUC-MG (1); PUC-RS (1); PUC-SP (1). ${ }^{16}$

Alguns artigos mencionam Virilio ao lado de outros autores para esclarecer a base teórica dos argumentos apresentados, sem avançar no pensamento do autor. Outros exploram seus conceitos de desterritorialização e multiterritorialidade, assim como os aspectos e consequências do fenômeno moderno que o autor chama glocal. Além disso, emerge o tema da transpolítica em relação à cibercultura, a partir da comparação entre a perspectiva de Virilio e a de Baudrillard. Os temas da rapidez e do futuro estão constantemente relacionados tanto nas obras do autor quanto nos artigos que o citam. 0 tempo real e sua relação fundamental com as tecnologias eletrônicas; a perspectiva distópica de um futuro imbricado pelas novas mídias; a velocidade da vida contemporânea e suas consequências são temas caros ao autor trabalhados em alguns artigos analisados.

\section{9) Howard Rheingold}

No recorte da pesquisa, Rheingold foi citado 16 vezes, em 12 artigos, por 13 pesquisadores e pesquisadoras de 7 instituições: UFES (4) ${ }^{17}$, UFRJ (3), UERJ (2), UFBA (1) UCS (1), UFPE (1), UFPB (1).

\footnotetext{
16 A soma do número de autores por instituição não é igual ao total de pesquisadores porque FRAGOSO, S. transita entre UFRGS e UNISINOS.

${ }^{17}$ Quatro autores que publicaram juntos em um mesmo artigo (Cf. GOVEIA, CIARELLI, CARREIRA, HERKENHOFF, 2014).
}

Dossiê Espaço Urbano e Imaginação Cultural - https://revistaecopos.eco.ufrj.br/

ISSN 2175-8689 - v. 22, n. 3, 2019

DOI: 10.29146/eco-pos.v22i3.23013 
Em quatro artigos, Rheingold é citado apenas como uma referência para ilustrar eventos e mudanças sociais causadas pela instauração das tecnologias de mobilidade e da possibilidade de uma ação coletiva conjunta online. Sua discussão é acionada para reforçar a ideia de que os dispositivos não são só dispositivos de tecnologias, mas também de práticas sociais.

Rheingold também é convocado para descrever, mesmo que brevemente, a formação dos flash mobs - as mobilizações momentâneas no espaço físico organizadas e coordenadas através das comunidades virtuais. Nesse sentido, sua obra é usada para apontar a potencialidade de satisfação e atração das comunidades virtuais no ciberespaço e para indicar a existência de sistemas de cooperação e reputação na Internet, além do que Rheingold chamou de dilemas de ação coletiva — problemas tratados coletivamente pelas comunidades e mobs.

\section{Considerações Finais}

O objetivo deste texto foi apresentar um mapeamento dos estudos voltados às novas mídias no Brasil, buscando identificar quais são os autores e autoras mais referenciados, bem como as principais perspectivas teóricas acionadas na compreensão dos fenômenos que compõem a Cibercultura. Se, como afirma Martino, "a expansão das mídias digitais, da Internet e da Cibercultura coloca um desafio epistemológico à Comunicação na constituição de um referencial para análise de fenômenos empíricos" (Martino, 2013, p.92-93), é fundamental apreender os aportes teóricos que vêm sendo acionados para compreender esse cenário contemporâneo transformado pelas tecnologias no campo da Comunicação.

Um olhar global à bibliografia e às teorias convocadas pelos trabalhos aqui analisados permite ressaltar alguns aspectos. Primeiramente, a existência de dois eixos mais fortes, que são: as discussões sobre tecnologia e a questão da técnica; e um viés político, centrado na questão do poder e controle. Neste sentido, é interessante observar que, dos 10 autores e autoras mais citados, há cinco filósofos

Dossiê Espaço Urbano e Imaginação Cultural - https://revistaecopos.eco.ufrj.br/

ISSN 2175-8689-v. 22, n. 3, 2019

DOI: 10.29146/eco-pos.v22i3.23013 
que não tratam de forma específica das novas mídias ou da Internet, e reforçam o viés da técnica e do controle - Foucault, Baudrillard, Deleuze, Flusser e Virilio. Os demais trazem contribuições mais específicas sobre o tema: Latour, Castells, Rheingold, Lemos e Santaella. Há aqui uma brasileira e um brasileiro, com destaque para Lemos, uma referência nacional na área da cibercultura.

É importante destacar a influência do pensamento francês na pesquisa sobre novas mídias no Brasil: Foucault, Baudrillard, Latour, Virilio e Deleuze (os dois últimos influenciados pelo primeiro), responsáveis por um pensamento crítico e mais pessimista sobre a sociedade ocidental moderna, colocando sob suspeição o potencial de controle das tecnologias. Entre os franceses, Baudrillard, Deleuze e Virilio apresentam uma influência mais pontual e localizada em certas instituições, enquanto Foucault aparece como uma referência mais amplamente compartilhada para a área.

Uma leitura das potencialidades da tecnologia na sociedade contemporânea emerge nos autores que tratam de forma mais específica da Internet: Castells, Rheingold e também Lemos. Castells faz a aproximação entre redes digitais e movimentos sociais; Rheingold traz a associação entre a mobilidade das redes e as mobilizações no espaço físico; Lemos relaciona tecnologias e sociabilidade. Outra temática que é trazida pelos autores é a relação das tecnologias com espaço e tempo. A perspectiva política é forte, porém mais do que uma crítica à estrutura da sociedade (e a um esquema de dominação de classes), delineia-se mais propriamente um poder que limita a liberdade dos indivíduos e constitui subjetividades disciplinadas.

Em síntese, a ênfase trabalhada pelas matrizes teóricas acionadas pelos pesquisadores e pesquisadoras do GT Comunicação e Cibercultura é a questão da técnica associada à questão do poder (controle), buscando compreender o papel das novas tecnologias na configuração da sociedade, da subjetividade dos indivíduos e de seus processos cognitivos. Enfim, suas potencialidades e suas ameaças. Como foi ressaltado pelo texto de Recuero (2015), nos últimos anos, os estudos têm focado

\footnotetext{
Dossiê Espaç̧o Urbano e Imaginação Cultural - https://revistaecopos.eco.ufrj.br/

ISSN 2175-8689 - v. 22, n. 3, 2019

DOI: 10.29146/eco-pos.v22i3.23013
} 
mais particularmente na análise das redes sociais e de novos dispositivos (Twitter, Facebook), o que tende a alargar o leque de referências e temáticas desse campo de reflexão.

\section{Referências bibliográficas}

CORRÊA, D. Estudos sobre Comunicação e Cibercultura no Brasil: conceitos, tendências e clusters. Razón y Palabra, v. 53, outubro/novembro, 2006.

DELEUZE, G; GUATTARI, F. Mil Platôs - Capitalismo e Esquizofrenia. Vol.1. São Paulo: Editora 34, 1995a.

FRANÇA, V. R. V. et al. Tendências das teorias da Comunicação: mapeamento de campos teóricos contemporâneos. Questões Transversais, São Leopoldo-RS, v.4 , n. 8, p. 57-67, 2016.

FRANÇA, V. R. V. et al. Comunicação e Política: mapeando autores/as e teorias mobilizados no Brasil. Compolítica, v. 8 n. 2, p. 5-40, 2018.

LEMOS, A. Cibercultura: tecnologia e vida social na cultura contemporânea. Porto Alegre: Sulina, 2002.

MARTINO, L. M. Repensando a(s) teoria(s) da Cibercultura: articulações e tensões com as teorias da Comunicação. Questões Transversais, v. 1, n. 2, julhodezembro/2013

RECUERO, R. GT de Cibercultura da Compós: Análise de Temas e Coautorias. InTexto, v. 1, p. 553-570, 2015.

SIMÕES, P. G. et al. Estudos de Televisão no Brasil: uma Abordagem de Autores/as e teorias. Contemporânea, v. 17, n. 2, p. 190-213, 2019.

RHEINGOLD, H. Smart Mobs: the next social revolution. New York: Basic Books, 2003.

Dossiê Espaço Urbano e Imaginação Cultural - https://revistaecopos.eco.ufrj.br/

ISSN 2175-8689-v. 22, n. 3, 2019

DOI: 10.29146/eco-pos.v22i3.23013 